\title{
Remote Memory and Cortical Synaptic Plasticity Require Neuronal CCCTC-Binding Factor (CTCF)
}

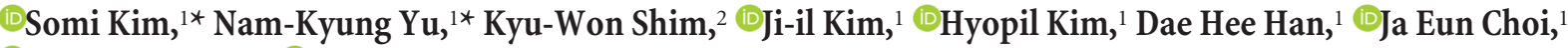 \\ (D) Seung-Woo Lee, ${ }^{1}$ DDong Il Choi, ${ }^{1}$ Myung Won Kim, ${ }^{1}$ Dong-Sung Lee, ${ }^{3}$ Kyungmin Lee, ${ }^{4}$ Niels Galjart, ${ }^{5}$ \\ (D) Yong-Seok Lee, ${ }^{6}$ DDae-Hyung Lee, ${ }^{7}$ and ${ }^{D}$ Bong-Kiun Kaang ${ }^{1}$ \\ ${ }^{1}$ Department of Biological Sciences, College of Natural Sciences, Seoul National University, Seoul 08826, South Korea, ${ }^{2}$ Interdisciplinary Program in \\ Bioinformatics, Seoul National University, Seoul 08826, South Korea, ${ }^{3}$ Salk Institute for Biological Studies, La Jolla, California 92130, ${ }^{4}$ Department of \\ Anatomy, Graduate School of Medicine, Kyungpook National University, Daegu 700-422, Korea, ${ }^{5}$ Department of Cell Biology and Genetics, 3000 CA \\ Rotterdam, The Netherlands, ${ }^{6}$ Department of Physiology, Seoul National University College of Medicine, Seoul 03080, South Korea, and ${ }^{7}$ Department of Life \\ and Nanopharmaceutical Sciences, Department of Maxillofacial Biomedical Engineering, School of Dentistry, Kyung Hee University, Seoul 02447, South Korea
}

The molecular mechanism of long-term memory has been extensively studied in the context of the hippocampus-dependent recent memory examined within several days. However, months-old remote memory maintained in the cortex for long-term has not been investigated much at the molecular level yet. Various epigenetic mechanisms are known to be important for long-term memory, but how the 3D chromatin architecture and its regulator molecules contribute to neuronal plasticity and systems consolidation is still largely unknown. CCCTC-binding factor (CTCF) is an 11-zinc finger protein well known for its role as a genome architecture molecule. Male conditional knock-out mice in which CTCF is lost in excitatory neurons during adulthood showed normal recent memory in the contextual fear conditioning and spatial water maze tasks. However, they showed remarkable impairments in remote memory in both tasks. Underlying the remote memory-specific phenotypes, we observed that female CTCF conditional knock-out mice exhibit disrupted cortical LTP, but not hippocampal LTP. Similarly, we observed that CTCF deletion in inhibitory neurons caused partial impairment of remote memory. Through RNA sequencing, we observed that CTCF knockdown in cortical neuron culture caused altered expression of genes that are highly involved in cell adhesion, synaptic plasticity, and memory. These results suggest that remote memory storage in the cortex requires CTCF-mediated gene regulation in neurons, whereas recent memory formation in the hippocampus does not.

Key words: 3D genome architecture; cortical plasticity; CTCF; remote memory; systems consolidation

Significance Statement

CCCTC-binding factor (CTCF) is a well-known 3D genome architectural protein that regulates gene expression. Here, we use two different CTCF conditional knock-out mouse lines and reveal, for the first time, that CTCF is critically involved in the regulation of remote memory. We also show that CTCF is necessary for appropriate expression of genes, many of which we found to be involved in the learning- and memory-related processes. Our study provides behavioral and physiological evidence for the involvement of CTCF-mediated gene regulation in the remote long-term memory and elucidates our understanding of systems consolidation mechanisms.

\section{Introduction}

The formation of long-term memory in the brain involves dynamic gene regulation through multiple layers of mechanisms.
This has been established based on studies focusing on the recent long-term memory, which is typically examined one to several days after learning (Lee et al., 2007; Huang et al., 2013; Nagayoshi et al., 2017). However, memory is believed to be further pro-

\footnotetext{
Received Sept. 21, 2017; revised March 30, 2018; accepted April 8, 2018.

Author contributions: B.-K.K., N.-K.Y., K.L., Y.-S.L., J.-H.L., N.G., and S.K. designed research; N.-K.Y., K.-W.S. D.-H.H., H.K., J.E.C., J.-i.K., S.-W.L., D.I.C., M.W.K., J.-H.L., and S.K. performed research; N.-K.Y., K.-W.S., D.H.H., H.K., J.E.C., J.-i.K., S.-W.L., D.I.C., M.W.K., J.-H.L., S.K., and D.-S.L. analyzed data; B.-K.K., N.-K.Y., K.L., Y.-S.L., J.-H.L., and S.K. wrote the paper.

This work was supported by the National Research Foundation of Korea, Korean Government Grant NRF2012R1A3A1050385 to B.-K.K. J.-i.K. was supported by the POSCO T.J. Park Foundation. N.-K.Y. was supported by L'Oreal Korea-UNESCO Women in Science Fellowship and L'Oreal-UNESCO Rising Talent Award.
}

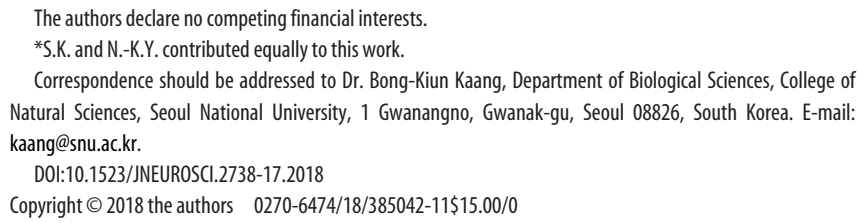


A

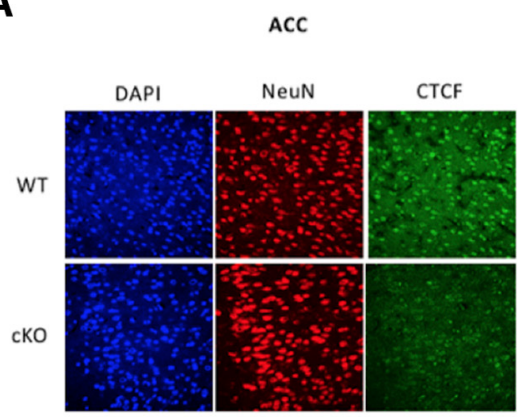

C

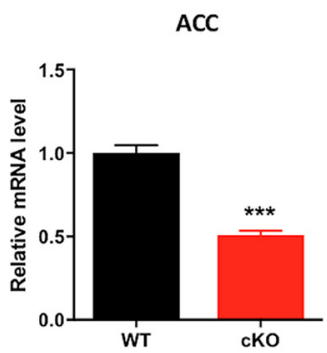

B

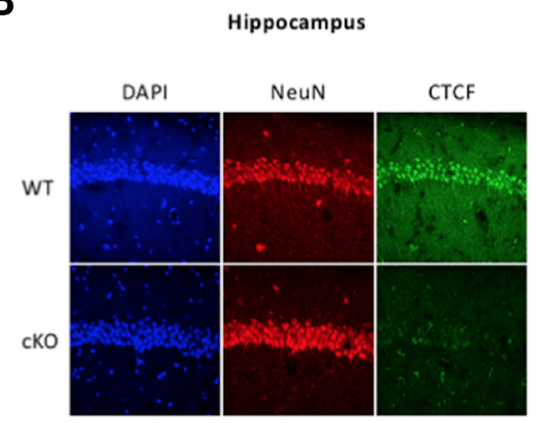

D

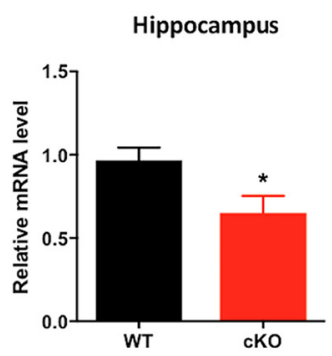

Figure 1. CTCF CKO mice have reduced expression of CTCF. $A, B$, Immunohistochemistry analysis showed that CTCF cKO mice have reduced CTCF protein expression in the ACC and hippocampus. Blue represents DAPI. Red represents NeuN. Green represents CTCF. C, D, qRT-PCR analysis confirmed that CTCF mRNA level is reduced in CTCF cKO mice (WT, $n=4 ;$ cKO, $n=3 ; \boldsymbol{C}$, WT, $1 \pm$ 0.0471 ; $c K 0,0.5094 \pm 0.025$; unpaired $t$ test; $p=0.0004 ; D$, WT, $0.9674 \pm 0.076$; $c K 0,0.6512 \pm 0.102$; unpaired $t$ test; $p=0.0257){ }^{*} p<0.05,{ }^{* * *} p<0.001$.

cessed into remote long-term memory over several weeks after the initial consolidation, during which the major brain region preserving the memory is shifted from the hippocampus to the cortex; this process is called systems consolidation (Frankland et al., 2004; Wang et al., 2006). During systems consolidation, cortical neural circuits bearing memory traces are reorganized and strengthened, leading to stabilization of the memory for longterm storage.

For the expression of remote memory, anterior cingulate cortex (ACC) has been noted to be particularly important among several brain regions (Einarsson et al., 2015). Several studies have shown that ACC is critical for remote fear and spatial memories (Frankland et al., 2004; Teixeira et al., 2006). More recent studies have shown that optogenetic inhibition of ACC (Goshen et al., 2011) and a disruption of spine growth in ACC (Restivo et al., 2009) block the contextual fear memory, suggesting that structural modifications in ACC are important for remodeling of long-range cortical connections during systems consolidation. Some previous studies have shown that epigenetic mechanisms are involved in systems consolidation. For example, cortical DNA methylation and histone acetylation participate in the formation and/or maintenance of remote memory (Miller et al., 2010; Yu et al., 2011; Peixoto and Abel, 2013). However, much of systems consolidation process still remains elusive, and the exact molecular underpinning of how remote memory is regulated is yet to be discovered.

Recently, 3D genome architecture has been receiving increasing attention in the research on epigenetic mechanisms (Bonev and Cavalli, 2016). 3D genome organization allows chromatin interaction within the topologically associating domains, which are genomic regions that frequently make contacts within themselves (Pombo and Dillon, 2015). This provides important structural bases for gene regulation, thereby contributing to the cell typespecific gene expression (Bouwman and de Laat, 2015). In both mouse models and human patients, the disruption of $3 \mathrm{D}$ chromatin architecture has been shown to be associated with neuropsychiatric diseases, such as Alzheimer's disease, post-traumatic stress disorder, and schizophrenia (Medrano-Fernández and Barco, 2016). However, the role of 3D chromatin architecture in remote memory has not been addressed to date.

Among several chromatin architecture regulators, CTCF is one of the most well-characterized proteins. CTCF exhibits an insulator activity, which guards genes from inappropriate chromatin interactions (Gaszner and Felsenfeld, 2006). CTCF recognizes the consensus sequence CCGCGNGGNGGCAG using 11 zinc finger motifs (Kim et al., 2007) and can bind to various sequences through combinations of its zinc fingers (Filippova et al., 1996). Chromatin immunoprecipitation experiments combined with high-throughput sequencing (ChIP-seq) have mapped CTCF binding activities in diverse tissues, revealing that CTCF can bind to 55,00065,000 sites on the mammalian genome (Ong and Corces, 2014). CTCF binds to enhancers, gene promoters, and gene bodies to regulate genome architecture (Holwerda and de Laat, 2013; Nichols and Corces, 2015), and its binding site occupancy is modulated by epigenetic processes, such as DNA methylation (Maurano et al., 2015). As many of the CTCF binding sites are located near genes (Hirayama et al., 2012), CTCF forms chromatin loops with other transcription factors, such as cohesion, and regulate transcription (Guo et al., 2012). Also, it has been shown that the orientation of CTCFbinding sites is highly correlated to chromatin loops and 3D organization of the genome (Guo et al., 2015). As CTCFmediated genome architecture mediates nuclear processes, such as enhancer-promoter interactions and alternative splicing (Kornblihtt, 2012; Ren et al., 2017), CTCF acts as a linker protein that connects the genome architecture to its function.

In this study, we examined two CTCF-deficient mouse models to explore a novel role of CTCF in systems consolidation.

\section{Materials and Methods}

Animals

CTCF conditional knock-out (cKO) mice were generated by crossing $\mathrm{CTCFfl} /{ }^{+}$; CaMKII $\alpha \mathrm{Cre} /{ }^{+}$with CTCFfl ${ }^{+}$; $\mathrm{CaMKII} \alpha{ }^{+/+}$. Heterozygous CTCF (HT) mice were generated by crossing $\mathrm{CTCFfl} /{ }^{+}$with VgatCre $/{ }^{+}$. Littermates that did not carry the Cre transgene or the floxed CTCF were used as controls. The 12- to 15-week-old adult male and female mice were used for the molecular, behavioral, and electrophysiological experiments. All animals were housed under a $12 \mathrm{~h}$ light/dark cycle with food and water provided ad libitum. The Animal Care and Use Committee of Seoul National University approved the animal protocols.

\section{Behavioral tests}

Male mice at 12-15 weeks of age were used for the behavioral analyses in this study. The behavioral experiments were performed essentially following our previous study (Kim et al., 2016). For the Morris water maze (MWM), mice were handled daily for 3 min over a week before training. The water maze was a gray cylinder-shaped tank $(140 \mathrm{~cm}$ diameter, 100 $\mathrm{cm}$ height) placed in a room with multiple spatial cues and dim light. Water mixed with white paint $\left(19^{\circ} \mathrm{C}-21^{\circ} \mathrm{C}\right)$ was filled up to $1 \mathrm{~cm}$ above 
A

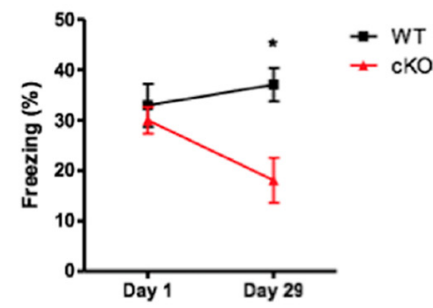

C

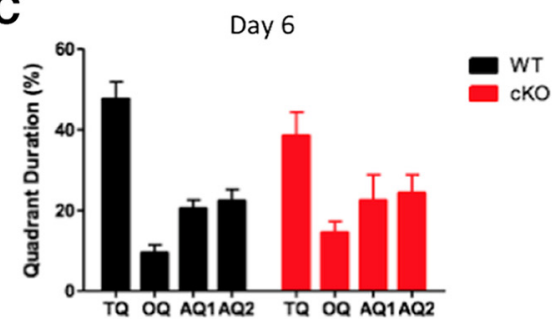

F

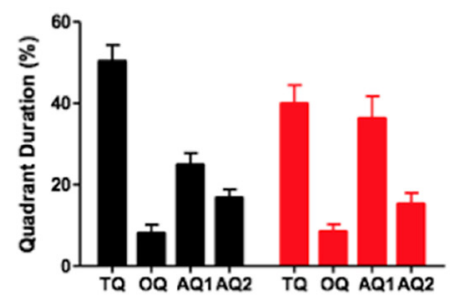

B

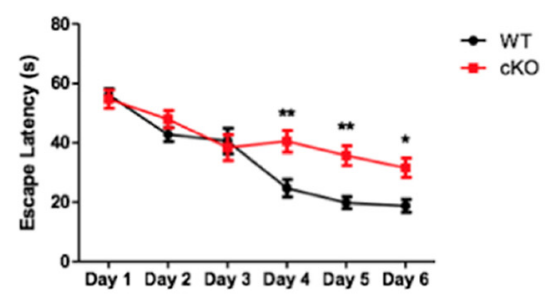

D

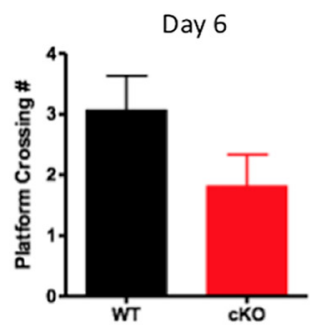

G

Day 27

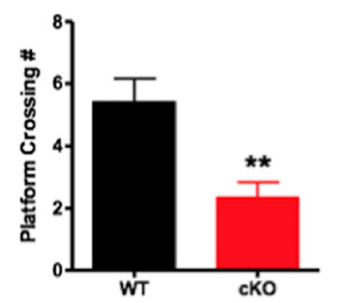

E

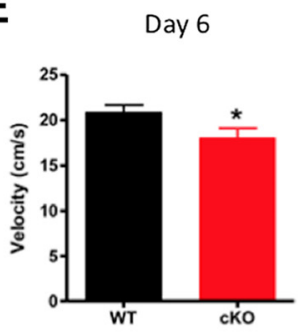

H

Day 27

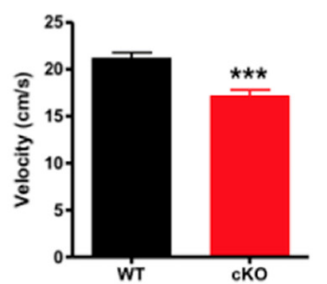

Figure 2. CTCF CKO mice display impaired cortex-dependent memory. $A$, In the CFC test, CTCF $c K 0$ mice showed intact recent fear memory but impaired remote fear memory $($ WT, $n=8 ; c K 0, n=$ 9; two-way repeated-measures ANOVA; effect of interaction, $F_{(1,15)}=9.831, p=0.0068$; Bonferroni post hoc test for day 29, $\left.p<0.01\right)$. $\boldsymbol{B}$, During the training phase of the MWM, (TCF cK0 mice showed longer escape latency on days $4-6$ (WT, $n=14 ; \mathrm{KK} 0, n=11$; two-way repeated-measures ANOVA, effect of interaction, $F_{(5,115)}=4.072, p=0.0019$; Bonferroni posthoc tests, day 4, $p<$ 0.01 ; day $5, p<0.01$; day $6, p<0.05)$. C $-\boldsymbol{E}$, In the recent memory probe test of the MWM test, CTCF cKO mice performed comparably with WT but showed slower swimming speed (C, two-way ANOVA, effect of interaction of genotype and quadrant, $F_{(3,92)}=1.246, p=0.2976 ; D, W T, 3.071 \pm 0.5593 ; \mathrm{CKO}, 1.818 \pm 0.5191 ;$ unpaired $t$ test; $p=0.1225 ; E, W T, 20.89 \pm 0.7795 ; \mathrm{CKO}, 18.04 \pm$ 1.063; unpaired $t$ test; $p=0.0370$ ). TQ, Target quadrant; $0 Q$, opposite quadrant; $A Q$, adjacent quadrant. $\boldsymbol{F}-\boldsymbol{H}$, When the same mice were tested 3 weeks after training, $C \mathrm{TCF}$ cKO mice displayed loss of spatial memory with less number of platform crossing and still showed slower swimming speed $\left(\boldsymbol{F}\right.$, two-way ANOVA, effect of interaction of genotype and quadrant, $F_{(3,92)}=3.551, p=0.0175$; G, WT, $5.429 \pm 0.7317 ;$; K0, $2.364 \pm 0.4724$; unpaired $t$ test; $p=0.0031 ; \boldsymbol{H}, \mathrm{WT}, 21.17 \pm 0.6098 ;$; $\mathrm{K} 0,17.16 \pm 0.6548$; unpaired $t$ test; $p=0.0002) .{ }^{*} p<0.05,{ }^{* *} p<0.01,{ }^{* * *} p<0.001$.

the escape platform (10 cm diameter). Mice were trained for four trials per day with $1 \mathrm{~min}$ intertrial intervals. Mice were placed into the different edge points of the maze in each four trials, facing the inner wall of the tank, and tracked using the Ethovision software (Noldus). The order of releasing point was changed daily. When mice reached the platform within $60 \mathrm{~s}$, they were removed from the maze and returned to the transport cage. When they failed, they were guided to or placed on the platform and were subsequently removed from the maze. After $5 \mathrm{~d}$ of training, a probe test was performed after removing the platform. Mice were placed at the center of the maze and tracked for $1 \mathrm{~min}$. One more session of training was performed after the probe test. To check the remote memory, the probe test was performed 4 weeks after the last training. For the contextual fear conditioning (CFC), mice were placed into the fear conditioning chamber (Coulbourne). After $148 \mathrm{~s}$, they received foot shocks ( $2 \mathrm{~s}, 0.75 \mathrm{~mA}$ ) twice with $30 \mathrm{~s}$ interval. After $30 \mathrm{~s}$, they were returned to the home cage. Contextual fear memory was tested by placing the mice again in the conditioning chamber and measuring the freezing levels (immobility) for $4 \mathrm{~min}$ using Freeze Frame software (Coulbourne).

\section{Electrophysiology}

Hippocampal fEPSP recording. fEPSP recordings were performed as described previously (Park et al., 2014). After anesthetization with isoflurane, mice were decapitated, and their brains were removed. Transverse hippocampal slices were sectioned $400 \mu \mathrm{m}$ thick using a vibratome (Leica). The slices were retained at $32^{\circ} \mathrm{C}$ for $30 \mathrm{~min}$ during the recovery period and then incubated at $28^{\circ} \mathrm{C}$ until the experiment. All incubation chambers were submerge-fashioned and the ACSF (124 mM NaCl, 2.5 $\mathrm{mm} \mathrm{KCl}, 1 \mathrm{~mm} \mathrm{NaH} \mathrm{PO}_{4}, 25 \mathrm{~mm} \mathrm{NaHCO}, 10 \mathrm{~mm}$ glucose, $2.6 \mathrm{~mm}$ $\mathrm{CaCl}_{2}, 1.3 \mathrm{mM} \mathrm{MgSO}_{4}$ ) was oxygenated with $95 \% \mathrm{O}_{2}$ and $5 \% \mathrm{CO}_{2}$ and perfused at $1 \mathrm{ml} / \mathrm{min}$ throughout the experiment. fEPSPs were recorded from the Schaffer collaterals of CA1. Stimuli were given every $30 \mathrm{~s}$ using concentric bipolar electrodes (MCE-100; Kopf Instruments), and the responses were recorded using a glass pipette electrode filled with ACSF $(1 \mathrm{M} \Omega$ ). Field potentials were amplified, low-pass filtered (GeneClamp 500; Molecular Devices), and then digitized (NI PCI-6221; National Instruments) for measurement. Data were monitored, analyzed online, and reanalyzed offline using the WinLTP program (WinLTP; winltp.com, University of Bristol, Bristol, UK). For the LTP and LTD experiments, stimulation was provided at the intensity that produces $\sim 40 \%$ of the slice's maximum slope. Two responses elicited per minute were averaged and expressed relative to an average of the $20 \mathrm{~min}$ baseline responses. Theta burst stimulation protocols were used to induce E-LTP and L-LTP (five pulses of $100 \mathrm{~Hz}$ repeated five times at $5 \mathrm{~Hz} ; 10 \mathrm{~s}$ intertrain interval used for E-LTP; 10 min intertrain interval for L-LTP). The fEPSP response average of the last 5 and 10 min of the E-LTP and L-LTP experiments were used to compare the level of synaptic plasticity between the groups.

ACC field potential recording using multielectrode array. For ACC multielectrode array experiments, three or four $300-\mu \mathrm{m}$-thick coronal brain slices after the corpus callosum connection were sectioned using a vibratome. The slices were incubated in a submerged chamber at room temperature until the experiment. ACSF $(124 \mathrm{~mm} \mathrm{NaCl}, 2.5 \mathrm{~mm} \mathrm{KCl}, 1$ 
A

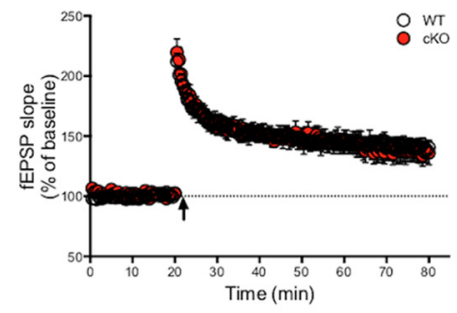

C

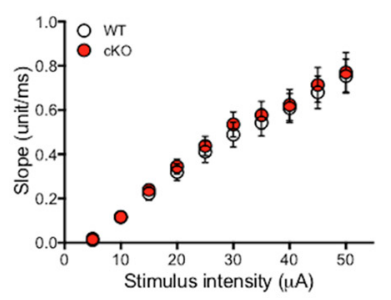

$\mathbf{E}$

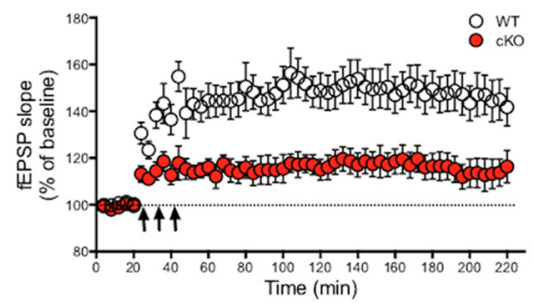

B

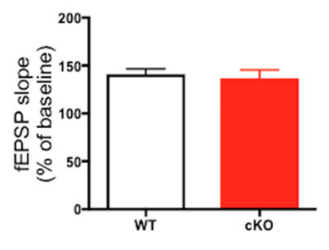

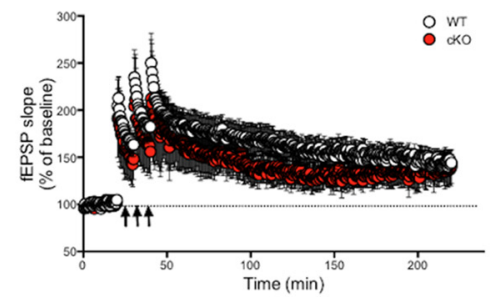

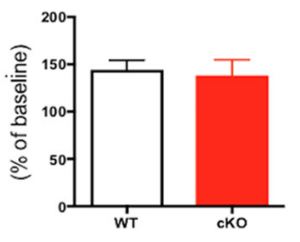

D

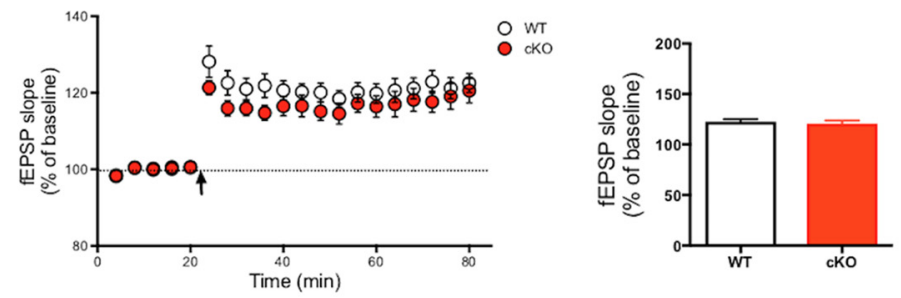

$\mathbf{F}$
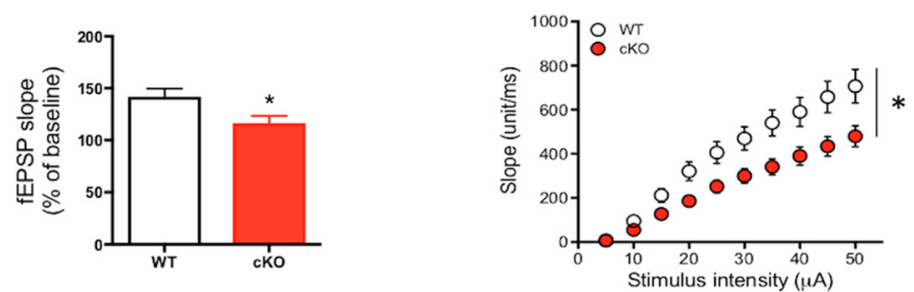

Figure 3. CTCF CKO mice exhibit impaired cortical synaptic plasticity. A, Hippocampal E-LTP was normal in CTCF cK0 mice (WT, $n=13 ;$; $K 0, n=8$; average of fEPSP slopes for the last 5 min; WT, $140.8 \pm 5.8 \%$; $C K 0,136.8 \pm 8.6 \%$; unpaired $t$ test; $p=0.6947) . B$, CTCF cKO mice did not exhibit any impairment in the theta burst stimulation-induced hippocampal L-LTP, and the potentiation level was maintained for $3 \mathrm{~h}$ at a comparable level with WT (WT, $n=5 ; \mathrm{KKO}, n=4$; average fEPSP slopes for the last $10 \mathrm{~min}$; WT, $144.0 \pm 10.4 \%$; $\mathrm{CK0}, 138.1 \pm 16.7 \%$; unpaired $t$ test; $p=0.7635$ ). C, Input- output curve was normal in CTCF CKO mice (WT, $n=11 ;$ KKO, $n=8$; repeated-measures two-way ANOVA, effect of genotype, $\left.F_{(1,17)}=0.0929 ; p=0.7641\right)$. D, (TCF cKO mice displayed normal cortical E-LTP (WT, $n=16 ; c K 0, n=12$; average of fEPSP slopes for the last $4 \mathrm{~min} ; \mathrm{WT}, 122.6 \pm 2.5 \%$; cK0, $120.6 \pm 3.2 \%$; unpaired $t$ test; $p=0.6190)$. $E$, (TCF cK0 mice showed a significant deficit in cortical L-LTP with a substantially decreased potentiation level after induction (WT, $n=10 ; \mathrm{CKO}, n=6$; average fEPSP slopes for the last 8 min; WT, $141.7 \pm 8.1 \%$; $\mathrm{KK} 0,116.4 \pm 6.9 \%$; unpaired $t$ test; $p=0.0498)$. $F$, Cortical basal transmission was attenuated in CTCF cKO mice (WT, $n=8$; cK0, $n=8$; repeated-measures two-way ANOVA, effect of genotype, $F_{(1,14)}=7.364$; $p=0.0168) .{ }^{*} p<0.05$.

$\mathrm{mm} \mathrm{NaH}_{2} \mathrm{PO}_{4}, 25 \mathrm{~mm} \mathrm{NaHCO}, 10 \mathrm{~mm}$ glucose, $2.5 \mathrm{~mm} \mathrm{CaCl}_{2}, 1 \mathrm{~mm}$ $\mathrm{MgSO}_{4}$ ) was oxygenated with $95 \% \mathrm{O}_{2}$ and $5 \% \mathrm{CO}_{2}$ and perfused at 2-3 $\mathrm{ml} / \mathrm{min}$ throughout the experiment. The MED64 system (Panasonic) was used as previously described (Kang et al., 2012). A slice was placed on the MED64 probe (MED-P515A, $8 \times 8$ array, interpolar distance 150 $\mu \mathrm{m}$, Panasonic) and perfused with ACSF at $28^{\circ} \mathrm{C}-30^{\circ} \mathrm{C}$. The electrical stimulation (1-20 $\mu \mathrm{m}, 0.2 \mathrm{~ms}$ ) was given to a channel in the deep layer region. MED64 Mobius was used for data acquisition and analysis. One pulse was given per minute, and the data were averaged every $4 \mathrm{~min}$. The percentages of the last $4 \mathrm{~min}$ (E-LTP) and $8 \mathrm{~min}$ (L-LTP) fEPSP slopes were normalized to the averaged value of the $20 \mathrm{~min}$ baseline.

\section{Western blot}

Mouse brain tissues were homogenized in RIPA buffer with the protease inhibitor mixture (Roche). The protein concentrations were measured using the BCA reagents (Thermo Fisher Scientific), and the equal amounts of proteins across animals were subjected to SDS-PAGE and transferred to nitrocellulose membrane. The CTCF protein was detected using the antibody (Abcam), and their levels were normalized to the GAPDH (Ambion) measured in the same lanes. The chemiluminescence of ECL substrate catalyzed by HRP-conjugated to the secondary antibody was detected and measured by ChemiDoc system (BMS).

\section{$q R T-P C R$}

Total RNA from tissues or cell culture was extracted using TRIZOL or RNAiso and reverse-transcribed using Superscript III following the manufacturers' instructions. Using the cDNA as templates, quantitative PCR was performed using SyBR premix ExTaqII (Takara) on ABI7300. The
$2^{-\mathrm{dCt}}$ method was used to measure the relative mRNA level of each gene of interest.

\section{RNA extraction and sequencing}

Total RNA from cultured cortical neurons was extracted, and the integrity and quality of the extracted RNA were assessed by BioAnalyzer. The standard protocol (Illumina) was used to make sequencing libraries for RNA-Seq. Using gel electrophoresis, $\sim 300 \mathrm{bp}$ fragments were isolated and amplified by PCR and sequenced using the HiSeq 2000 (Illumina) in the paired-end sequencing mode $(2 \times 101 \mathrm{bp})$.

RNA-Seq read processing and differential gene expression test RSEM (RNA-Seq by Expectation Maximization, version 1.2.28) ( $\mathrm{Li}$ and Dewey, 2011) was used to align the raw sequencing reads to the mm10 mouse genome. Only uniquely and properly mapped read pairs were used for further analysis. To assess gene expression levels, the transcript per million measure was calculated (Wagner et al., 2012) using the read counts of each gene annotated in Ensembl release 82 (Yates et al., 2016). The EdgeR package (Robinson et al., 2010) in R was used to identify the differentially expressed genes between the CTCF knockdown (KD; shCTCF) and wild-type (WT; shLacZ) samples. Differentially expressed genes were defined as those with changes of at least 1.2-fold between samples at a false discovery rate of 5\%. Gene ontology term enrichment analysis on the differentially expressed genes was executed through ToppGene Suite (https://toppgene.cchmc.org/) (Chen et al., 2009), and the network analysis was performed using QIAGEN's Ingenuity Pathway Analysis software (IPA, QIAGEN, www.qiagen.com/ingenuity). 
A

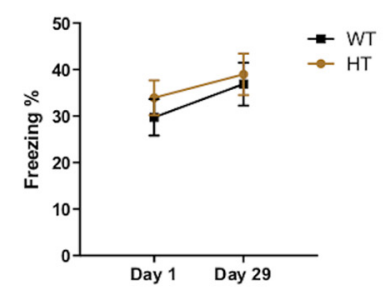

E

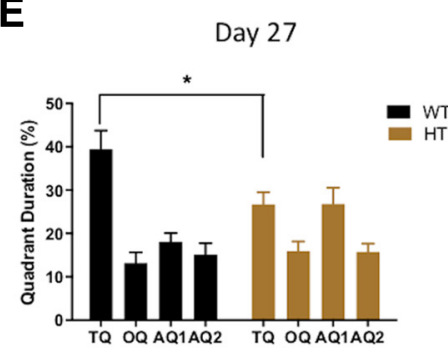

B

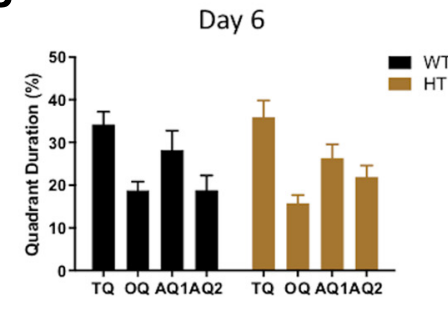

C

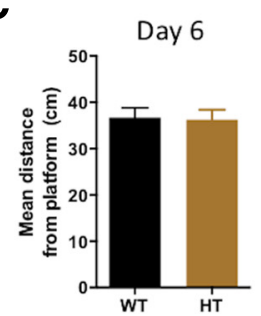

D

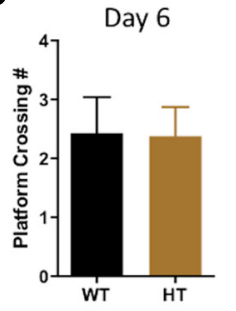

F

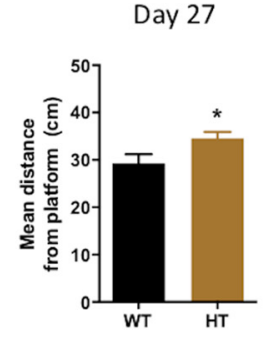

G

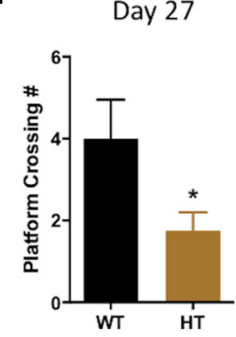

H
I

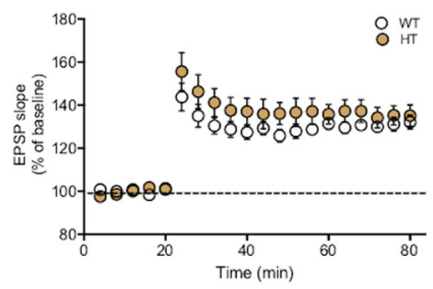

$\bigcirc_{H T}^{w T}$

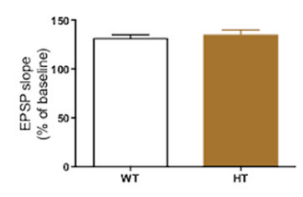

J

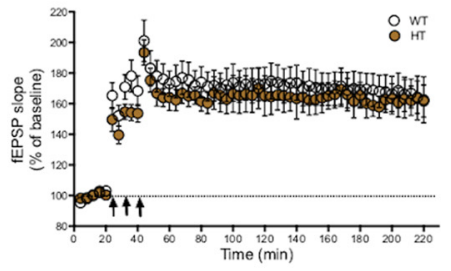

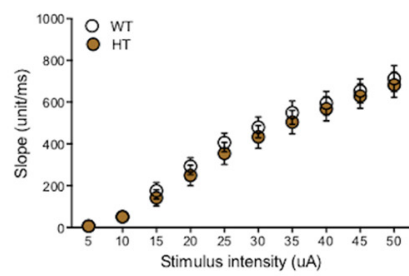

Figure 4. CTCF HT mice show a partial deficit in remote memory. $A$, CFC recent memory and remote memory were normal in CTCF HT mice (WT, $n=15 ; H T, n=16$; two-way ANOVA; effect of interaction, $\left.F_{(1,58)}=0.0631 ; p=0.8026\right) . \boldsymbol{B}-\boldsymbol{D}$, CTCF HT mice performed comparably with WT in the recent memory test of the MWM (WT, $n=7 ; \mathrm{HT}, n=8 ; \boldsymbol{B}$, two-way ANOVA; effect of interaction of genotype and quadrant, $F_{(3,52)}=0.4176 ; p=0.7411 ; C$, WT, $36.7 \pm 2.126 ; C K 0,36.24 \pm 2.155$; unpaired $t$ test; $p=0.8835 ; \boldsymbol{D}$, WT, $2.429 \pm 0.6117 ;$ HT, $2.375 \pm 0.4978 ;$ unpaired $t$ test; $p=$ 0.9463). $\boldsymbol{E}-\mathbf{G}$, Three weeks later, the CTCF HT mice showed a significant memory deficit in the MWM probe test. Quadrant duration, distance from platform, and number of platform crossings were all impaired (WT, $n=7 ; \mathrm{HT}, n=8 ; \boldsymbol{E}$, two-way ANOVA; effect of interaction of genotype and quadrant, $F_{(3,52)}=4.882 ; p=0.046$; Bonferroni post hoc test for TQ (target quadrant). $p=0.0124$; $\boldsymbol{F}, \mathrm{WT}, 29.23 \pm 1.985 ; \mathrm{HT}, 34.55 \pm 1.372 ;$ unpaired $t$ test $; p=0.0423 ; \mathbf{G}, \mathrm{WT}, 4 \pm 1.750 ; \mathrm{HT}, 1.750 \pm 0.4532$; unpaired $t$ test; $p=0.0442)$. $\boldsymbol{H}$, Basal transmission was normal in ACC of (TCF HT mice (WT, $n=10 ; \mathrm{HT}, n=11$; two-way ANOVA; effect of interaction, $\left.F_{(9,171)}=0.2952 ; p=0.9753\right)$. II E-LTP was intact in ACC of CTCF HT mice (WT, $n=7 ; \mathrm{HT}, n=6$; average fEPSP slopes for the last 4 min; WT, $132.1 \pm 3.252 \%$; HT, $135.1 \pm 5.005 \%$; unpaired $t$ test; $p=0.6123$ ). J, L-LTP was also normal in ACC of CTCF HT mice (WT, $n=6$; HT, $n=4$; average fEPSP slopes for the last $8 \mathrm{~min} ; \mathrm{WT}, 164.2 \pm 10.12 \% ; \mathrm{HT}, 159.8 \pm 9.665 \%$; unpaired $t$ test; $p=0.7700) .{ }^{*} p<0.05$.

Experimental design and statistical analysis

All experiments were performed in a blind fashion. We used the minimum number of mice that can produce statistical validity. For CTCF cKO mice experiments, we used 8-16 male mice for behavioral tests, 6-10 female mice for electrophysiology, and 3 male and 4 female mice for qRT-PCR experiments. For CTCF HT mice experiments, we used 15-31 male mice for behavioral tests and 10 female mice for electrophysiology.

Data were represented by the mean \pm SEM. For each variable, comparison of two groups was made using Student's $t$ test. Two-way ANOVA and post hoc Bonferroni test were used for further comparisons.

\section{Results}

Generation of CTCF cKO mice with CTCF deletion in forebrain excitatory neurons

Previously, Hirayama et al. (2012) demonstrated that the deletion of CTCF in cortical and hippocampal neurons during postnatal development causes abnormal neuronal development, obvious growth retardation, and early lethality within 4 weeks after birth. Because the early lethality prevents examining mice in behavioral and electrophysiological tests, we generated CTCF cKO mice by crossing the floxed CTCF line with CaMKIIa-Cre line, which expresses Cre recombinase in the forebrain excitatory neurons starting from 4 to 5 weeks of age. This enabled us to circumvent the lethal effect of postnatal CTCF deletion, and our CTCF cKO mice were viable at least until $\sim 8$ months of age with no apparent health abnormalities. We confirmed that CTCF expression is sufficiently reduced in the cortical and hippocampal excitatory neurons of the 12-week-old mice using immunohistochemistry (Fig. $1 A, B$ ) and qRT-PCR (Fig. 1C,D). The residual mRNA in the CTCF cKO mice shown in Figure $1 C, D$ is probably due to the intact mRNA expression in inhibitory neurons and glial cells. The CTCF cKO mice did not exhibit any abnormal level of anxiety or locomotion (data not shown).

\section{Impaired remote memory in CTCF cKO mice}

To examine whether the neuronal CTCF is needed for the formation of long-term memory, we trained CTCF cKO mice on hippocampus-dependent memory tasks. Subsequently, we tested the mice at two different time points: $1 \mathrm{~d}$ or 4 weeks after the behavioral training. When the CTCF cKO mice were first tested $1 \mathrm{~d}$ after the training in the CFC, they displayed comparable freezing levels to the WT mice (Fig. 2A). Similarly, in the MWM, the CTCF cKO mice exhibited normal spatial reference memory during the probe test (Fig. 2C,D). The CTCF cKO mice showed a delay in locating the hidden platform during the training (Fig. 
A

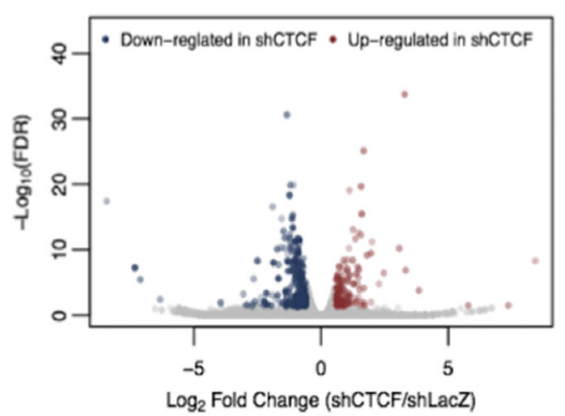

B

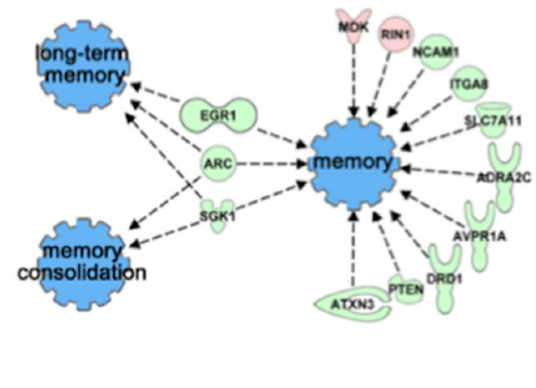

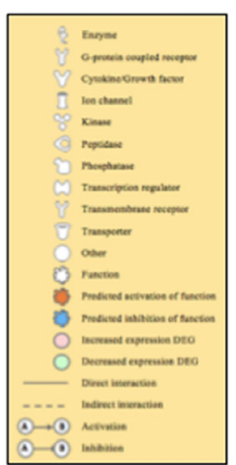

E

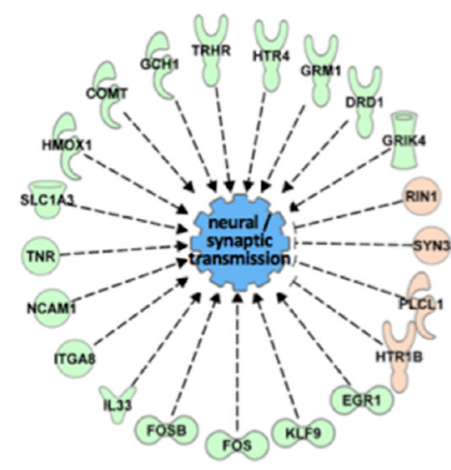

C

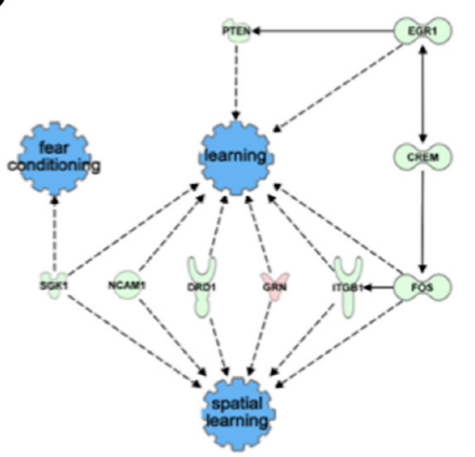

D

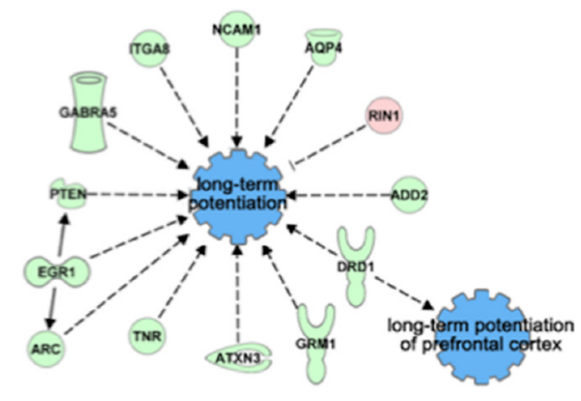

Figure 5. RNA-seq data from CTCF KD cortical culture reveal differentially expressed genes. $\boldsymbol{A}$, Volcano plot showed that more genes were downregulated than upregulated in the DEG list. $\boldsymbol{B}-\boldsymbol{E}$, IPA showed connections of DEGs for four functions: memory, learning, LTP, and synaptic transmission. They were all predicted to be inhibited.

$2 B)$, but it is unlikely that they had not learned the location of the platform because their performance level on the day 6 probe test was comparable with that of WT. Instead, the delay in the escape latency is likely due to the impaired swimming speed of the CTCF cKO mice (Fig. 2E,H). It is plausible to assume that CTCF mutant mice may have a mild motor deficit that has contributed to slower swimming speed but not to the performance on memory tests. After 4 weeks, we retested the same mice and found that the CTCF cKO mice have a significantly impaired remote memory. In the CFC, the CTCF cKO mice exhibited a lower level of freezing than the WT controls (Fig. 2A). Similarly, the CTCF cKO mice displayed reduced target quadrant duration and a lower count of platform crossing during the probe test (Fig. $2 F, G$ ). These results suggest that the CTCF in the adult forebrain excitatory neurons is not necessary for the formation of recent memory but is indispensable for the remote memory.

\section{Impaired cortical synaptic plasticity in the CTCF cKO mice} Next, we performed electrophysiological experiments to verify the underlying mechanisms of the remote memory deficit at the synaptic level. We chose hippocampal and ACC field recordings to compare the contribution of hippocampal and cortical LTP in the remote memory process. In the hippocampal slice recording, SC-CA1 E-LTP and L-LTP were induced normally and the potential levels stably lasted for 1 and $3 \mathrm{~h}$, respectively (Fig. $3 A, B$ ). We performed input-output curve and confirmed that hippocampal basal transmission is normal in CTCF cKO mice (Fig. $3 C)$. Together, these results suggest that the hippocampal deletion of CTCF does not affect the electrophysiological properties. Because these results are in line with the normal recent memory shown in CTCF cKO mice, we tested the cortical plasticity, which is a physiological trace of remote memory (Frankland and Bontempi, 2005). In the CTCF cKO ACC slices, E-LTP was normal
(Fig. 3D), whereas L-LTP appeared significantly impaired with a considerably lower potentiation level (Fig. $3 E$ ). Moreover, the basal transmission was also downregulated in CTCF cKO mice (Fig. $3 F$ ), indicating that CTCF has a region-specific role in regulating the basal transmission level. The slice recording results indicate that CTCF deletion specifically disrupts the cortical synaptic plasticity, which leads to impaired performance in remote memory behaviors. Our results provide physiological evidence of the shift from the hippocampus to the cortex as a core region in processing the remote memory.

\section{CTCF in inhibitory neurons also participate in remote memory maintenance}

Having found that the CTCF deletion in excitatory neurons induces remote memory deficits, we further examined the effect of CTCF deletion in the inhibitory neurons. We crossed the floxed CTCF line with the Vgat; Cre line to induce inhibitory neuronspecific deletion of CTCF during development. However, we found that homozygous CTCF KO mice were embryonic lethal and only HT mice survived. We concluded that, as in the previous report (Hirayama et al., 2012), the homozygous deletion of CTCF in inhibitory neurons during development has a lethal effect on the animals and confirmed that CTCF is crucial for development. We used the CTCF HT mice for the experiments. As with the CTCF cKO mice, we trained the CTCF HT mice in the MWM and $\mathrm{CFC}$ and examined recent and remote memory. In the CFC, the CTCF HT mice exhibited normal freezing level in both recent and remote memory tests (Fig. $4 A$ ). However, in the MWM, the CTCF HT mice displayed a significant impairment in finding the platform with a higher number of platform crossings in the probe test (Fig. 4E-G). The recent spatial memory was completely intact in the CTCF HT mice (Fig. $4 B-D$ ). These results indicated that the CTCF HT mice have a deficit in spatial remote memory and 
Table 1. List of the $\mathrm{GO}$ terms and categories in order of the smallest to the largest $q$ value

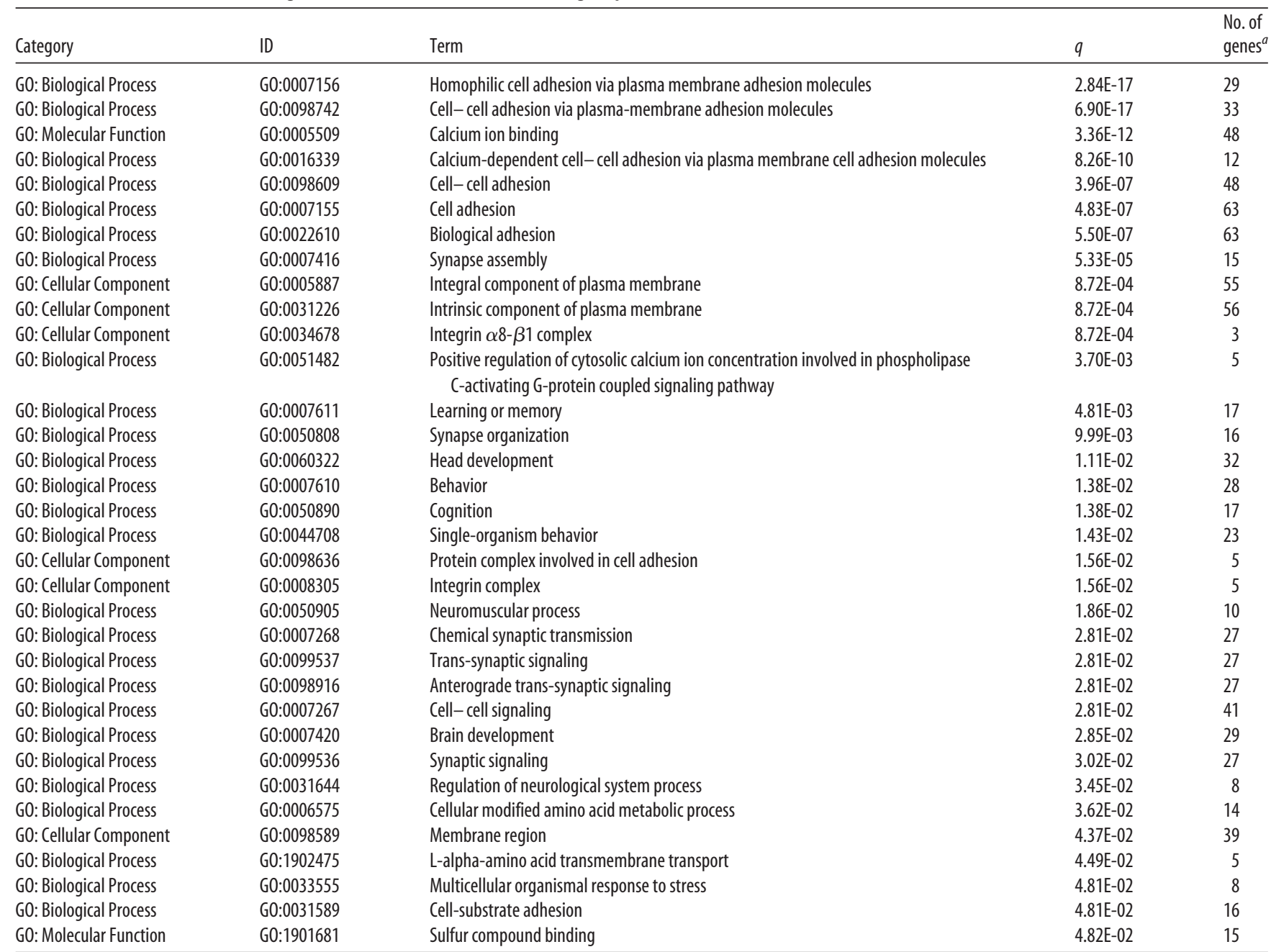

${ }^{a}$ Number of DEGs that fall into each $\mathrm{GO}$ term.

that CTCF in the inhibitory neurons is also involved in systems consolidation. The partial impairment may be due to an assumedly mild effect of the HT CTCF deletion compared with the homozygous deletion. The cortical basal transmission and LTP appeared normal in the CTCF HT mice (Fig. $4 H-J$ ), which indicate that CTCF dysfunction in inhibitory neurons did not affect the synaptic plasticity or postsynaptic potential of excitatory neurons.

\section{Gene expression profile changes upon CTCF deletion in cortical neuron culture}

To investigate the molecular changes underlying the phenotypes of the CTCF cKO and HT mice, we explored the variations in the gene expression profile. It is well established that appropriate gene expression is necessary for memory (Igaz et al., 2004; Peixoto and Abel, 2013). We induced CTCF KD in primary mouse cortical cultures using adeno-associated virus ( $\sim 67 \%$ mRNA reduction) and performed RNA sequencing (RNA-seq). We found a total of 394 differentially expressed genes (DEGs) in CTCF KD neurons with the fold change cutoff set to $>1.5$. Of the 394 DEGs, $146(37 \%)$ genes were upregulated, whereas 248 (63\%) genes were downregulated. This indicated a shift in the overall gene expression to a downregulating direction (Fig. 5A), which was similar to previous results of CTCF deletion studies (Wan et al., 2008; Hirayama et al., 2012). To analyze the DEGs from RNA-seq with unifying terminologies, we performed gene ontology analysis, which is a major bioinformatics technique that uses gene annotations to hierarchically classify the genes and their functions (Ashburner et al., 2000). We found that many of our DEGs are involved in cell adhesion, neuroactive ligand-receptor interaction, and calcium binding. More importantly, we found that genes that are involved in learning and memory, synapse assembly, and cognition were enriched in our DEG list (Table 1), suggesting that they were improperly expressed in the CTCFdeficient cells. For more detailed investigation, we performed IPA to connect the DEGs in pathways under certain terminologies, and we found that the IPA results exactly reflected the behavioral and electrophysiological phenotypes of our CTCF cKO and HT mice. Memory and learning were predicted to be functionally inhibited, and, specifically, long-term memory and memory consolidation appeared to be inhibited (Fig. 5 B, C). The expression of most of the DEGs functionally involved in LTP and synaptic transmission was decreased, leading to the inhibition of the two functions (Fig. 5D,E). Furthermore, in the DEG list, we found a highly frequent appearance of the clustered $P c d h$ family isoforms. There was a total of $27 P c d h$ genes, which made up $10 \%$ of the DEG list (Table 2). This pattern was similar to the previous microarray analysis data from Hirayama et al. (2012), indicating that CTCF critically regulates the neuronal Pcdh expression in adult as well as developmental brain. We performed qRT-PCR 
Table 2. List of the downregulated $P c d h$ isoforms ${ }^{a}$

\begin{tabular}{llll}
\hline ENSEMBL_ID & Gene_symbol & Fold change & FDR \\
\hline ENSMUSG00000104252 & Pcdha4 & 2.79603809 & $8.1255 \mathrm{E}-06$ \\
ENSMUSG00000104318 & Pcdha7 & 1.75131089 & $3.3856 \mathrm{E}-07$ \\
ENSMUSG00000103770 & Pcdha9 & 1.50533694 & 0.0170364 \\
ENSMUSG00000051599 & Pcdhb2 & 1.57070315 & 0.03101376 \\
ENSMUSG00000045498 & Pcdhb3 & 1.55631839 & 0.02999433 \\
ENSMUSG00000045689 & Pcdhb4 & 1.625148 & 0.00566807 \\
ENSMUSG00000063687 & Pcdhb5 & 2.09150871 & $4.5222 \mathrm{E}-09$ \\
ENSMUSG00000045062 & Pcdhb7 & 1.5490714 & 0.00072286 \\
ENSMUSG00000051242 & Pcdhb9 & 2.21286193 & $1.8998 \mathrm{E}-15$ \\
ENSMUSG00000045657 & Pcdhb10 & 1.65599862 & 0.00078325 \\
ENSMUSG00000051486 & Pcdhb11 & 1.88906083 & $6.1688 \mathrm{E}-09$ \\
ENSMUSG00000043458 & Pcdhb12 & 2.19555803 & $2.6991 \mathrm{E}-07$ \\
ENSMUSG00000047307 & Pcdhb13 & 2.44499604 & $9.4975 \mathrm{E}-09$ \\
ENSMUSG00000047033 & Pcdhb15 & 1.53833238 & 0.04003896 \\
ENSMUSG00000047910 & Pcdhb16 & 1.68348686 & $2.4564 \mathrm{E}-06$ \\
ENSMUSG00000046387 & Pcdhb17 & 1.5461865 & 0.00016953 \\
ENSMUSG00000048347 & Pcdhb18 & 1.65724535 & $3.5439 \mathrm{E}-06$ \\
ENSMUSG00000043313 & Pcdhb19 & 1.90074633 & $1.314 \mathrm{E}-11$ \\
ENSMUSG00000046191 & Pcdhb20 & 1.62866281 & $8.2162 \mathrm{E}-05$ \\
ENSMUSG00000044022 & Pcdhb21 & 2.14201216 & $2.8263 \mathrm{E}-08$ \\
ENSMUSG00000073591 & Pcdhb22 & 1.8448699 & $3.0912 \mathrm{E}-10$ \\
ENSMUSG00000103144 & Pcdhga1 & 1.8666182 & $3.0912 \mathrm{E}-10$ \\
ENSMUSG00000103332 & Pcdhga2 & 1.65288697 & $5.3454 \mathrm{E}-07$ \\
ENSMUSG00000102440 & Pcdhga9 & 1.50955405 & 0.00326747 \\
ENSMUSG00000102428 & Pcdhga12 & 2.02084532 & $6.2239 \mathrm{E}-12$ \\
ENSMUSG00000103037 & Pcdhgb1 & 1.75647878 & $4.0811 \mathrm{E}-06$ \\
ENSMUSG00000050505 & Pcdh20 & 1.57880867 & 0.00362815 \\
\hline
\end{tabular}

$\bar{a}$ In the gene expression analysis, CTCF KD neurons exhibited a total number of $27 \mathrm{Pcdh}$ isoforms with decreased expression. Fold changes indicate the degree of the expressional downregulation. Of the clustered $P c d h$ isoforms, 18 $P c d h \beta(66 \%), 5 P c d h \gamma(19 \%)$, and $3 P c d h \alpha(11 \%)$ were found. There was only one nonclustered $P c d h$ isoform.

experiments using the ACC tissues from CTCF cKO mice and ratified that the effects of CTCF deletion in the cortical culture are similar to those of CTCF deletion in vivo (Fig. $6 A-E$ ). Moreover, we performed qRT-PCR for the same genes using the hippocampal tissues from CTCF cKO mice to compare the results with that of ACC. We found that expressions of Drd1, Pcdh $\alpha 4, \operatorname{Pcdh} \beta 13$, and $P c d h \gamma A 12$ are significantly decreased or show a tendency of decrease (Fig. 6G-J), as they were in ACC. However, the expression of $R h o U$ was comparable with that of WT in hippocampus (Fig. 6F). This finding represents a gene expressional difference between hippocampus and ACC caused by CTCF dysfunction, supporting our conclusion that CTCF plays region-specific roles for regulation of remote memory. Together, the RNA-seq data and bioinformatics analysis suggest that CTCF deletion alters the expression of a set of genes, which leads to defects in the cortical plasticity and remote memory in CTCF-deficient mice.

\section{Discussion}

How long-lasting memory is formed and maintained in the brain through systems consolidation is a critical question extensively explored in neurobiology. However, the mechanisms are still largely in veil. To investigate how memory traces are retained for a long time, it is important to examine long-lasting geneexpression changes. Our CTCF cKO mice bearing the deletion of CTCF in mature excitatory neurons developed normally with impaired remote memory and cortical late-LTP. Similarly, the CTCF deletion in inhibitory neurons caused a remote memoryspecific deficit in the spatial memory behavioral task. In accordance with these results, the mRNA level of genes related to learning and memory were downregulated in CTCF-deficient neurons. Together, these results suggest that CTCF has a critical function in regulation of long-term memory storage and maintenance in both excitatory or inhibitory neurons.

In this study, we also provide evidence that CTCF may have a differential role in hippocampus and ACC for remote memory reregulation. Our qRT-PCR results showed that the expression of $R h o U$ is regulated by CTCF in ACC but not in hippocampus. This is in line with our behavioral and physiological results from CTCF-deficient mice because remote memory formation is known to more heavily rely on cortical networks (TakeharaNishiuchi et al., 2006) and functional plasticity in cortical regions (Headley and Paré, 2017). Further analysis on CTCF's gene expressional regulation in hippocampus and ACC will provide an insight into region-specific mechanisms in systems consolidation. Frankland et al. (2001) provided one of the early studies on molecular mechanisms of permanent cortical memory. Using $\alpha$-CaMKII ${ }^{+/-}$mutant mice, they revealed that fear and spatial remote memories depend on persistent activation of cortical traces and that $\alpha$-CaMKII-dependent LTP is required for cortical memory consolidation. More recently, Rossetti et al. (2017) discovered that CaMKII is not only required for memory formation but also for memory storage and LTP maintenance through a memory erasure experiment. Similarly, we showed in this study that CTCF-dependent gene expression in ACC is important for cortical synaptic plasticity and remote memory consolidation. As with CaMKII, further analysis on time-dependent CTCFinduced gene expression will reveal how CTCF is involved in different phases of consolidation process and stabilization of remote memory.

Recently, Sams et al. (2016) reported on the role of CTCF in hippocampus-dependent memory. They created CTCF cKO mice using a similar strategy of crossing the floxed CTCF mice with CaMKIIa-Cre line to inhibit the CTCF expression in postmitotic excitatory neurons. However, their results were partially and yet significantly different from our present results. These discrepancies may be due to several factors, and we think that it is noteworthy to go over the differences. While Sams et al. (2016) similarly reported memory-related deficits in the CTCF cKO mice, they showed that the Cre-dependent CTCF deletion started at 1 week of age and a significant decrease of the protein level was reached by 8 weeks of age. However, our CaMKIIa-Cre line started its Cre expression at 4 weeks of age as previously reported (Tsien et al., 1996; Liu et al., 2010), and a sufficient level of protein reduction was only reached at 12 weeks of age (Fig. $1 C$ ). Therefore, for most of the experiments, Sams et al. (2016) used 10- to 12-week-old CTCF cKO mice, whereas we used 12- to 15-weekold mice, which had avoided developmental effects of the gene deletion. Furthermore, Sams et al. (2016) reported that their CTCF cKO mice died after 17 weeks of age with weight loss, whereas our CTCF cKO mice were viable for $>40$ weeks of age and exhibited no apparent health abnormalities. In addition to physical phenotypes, the memory-related deficits also appeared to be different between the two studies. The CTCF cKO mice in the Sams et al. (2016) study exhibited impaired hippocampal LTP with disrupted recent memory in the cued fear conditioning and MWM tests. However, our CTCF cKO mice exhibited normal hippocampus-dependent phenotypes with dramatically impaired cortex-dependent remote memory. Moreover, while the RNA-seq data showed a similar result in Pcdh expression change, Sams et al. (2016) showed a higher number of upregulated genes, and our present study had a higher number of downregulated genes in the DEG list. In summary, Sams et al. (2016) focused on investigating the effect of CTCF deletion early in life and its roles in the hippocampus, whereas we focused on the effect of CTCF 
A

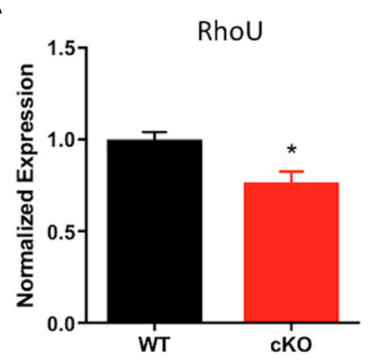

D

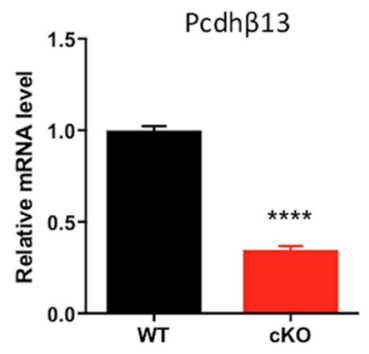

G

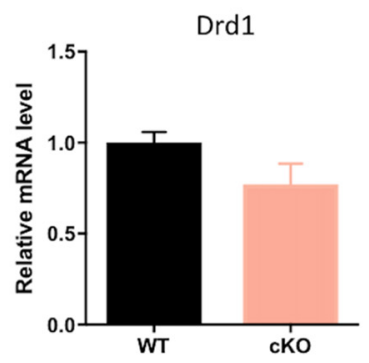

B

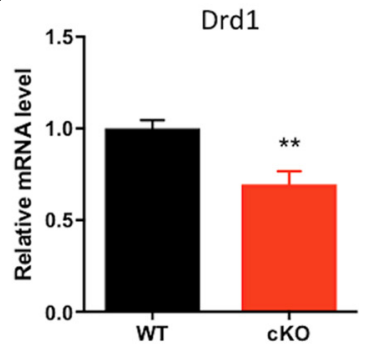

E

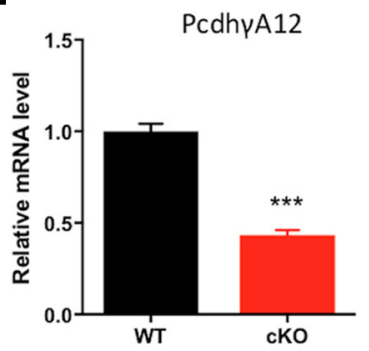

H

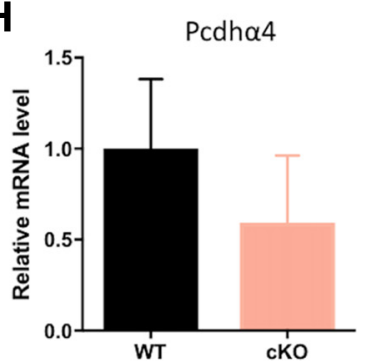

C

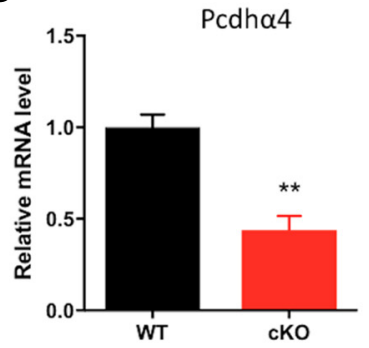

F

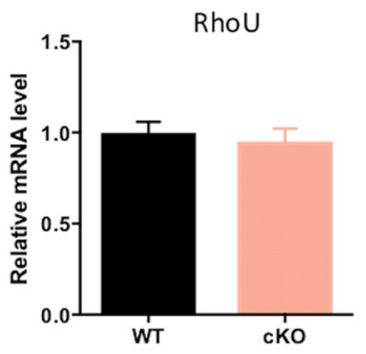

I

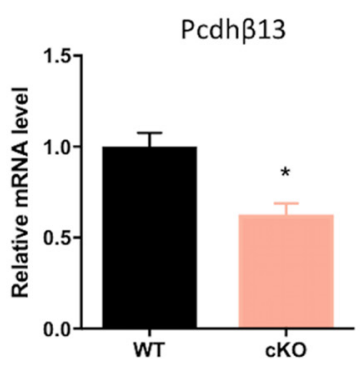

J

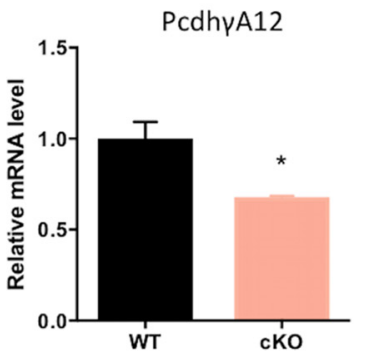

Figure 6. qRT-PCR of 5 DEGs shows differential results in ACC and hippocampus. A-E, qRT-PCR of ACC tissues from CTCF cKO mice confirmed the RNA-seq data of gene downregulation (WT, $n=$ $4 ; \mathrm{KK}, n=3 ; \boldsymbol{A}$, normalized expression of RhoU mRNA; WT, $1 \pm 0.04013 \%$; $\mathrm{KK} 0,0.7669 \pm 0.05816 \%$; unpaired $t$ test; $p=0.0187 ; \boldsymbol{B}$, normalized expression of Drd $1 \mathrm{mRNA}$; WT, $1 \pm 0.07316 \%$; cK0, $0.6552 \pm 0.1332 \%$; unpaired $t$ test; $p=0.0584$; C, normalized expression of Pcdh $\alpha 4$ mRNA; WT, $1 \pm 0.06878 \%$; KO, $0.4386 \pm 0.07655 \%$; unpaired $t$ test; $p=0.0029 ; \boldsymbol{D}$, normalized expression of Pcdh $\beta 13 \mathrm{mRNA}$; WT, $1 \pm 0.02351 \%$; $c K 0,0.3466 \pm 0.02203 \%$; unpaired $t$ test; $p<0.0001 ; \boldsymbol{E}$, normalized expression of Pcdh $\gamma A 12 \mathrm{mRNA} ; \mathrm{WT}, 1 \pm 0.04239 \% ; c K 0,0.4336 \pm$ $0.02648 \%$; unpaired $t$ test; $p=0.0001$ ). $\boldsymbol{F}$-J, qRT-PCR of hippocampal tissues from CTCF cK0 mice showed a different pattern of gene expression (WT, $n=4 ;$; KO, $n=3 ; \boldsymbol{F}$, normalized expression

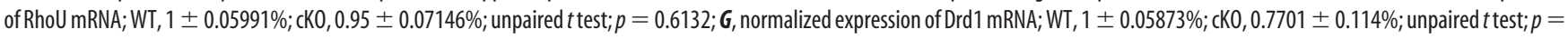
$0.1090 ; \boldsymbol{H}$, normalized expression of Pcdh $\alpha 4 \mathrm{mRNA}$; WT, $1 \pm 0.3823 \% ; \mathrm{KK} 0,0.593 \pm 0.3689 \%$; unpaired $t$ test; $p=0.4907 ; \boldsymbol{I}$, normalized expression of Pcdh $\beta 13 \mathrm{mRNA}$; WT, $1 \pm 0.07615 \%$; $c K 0$, $0.6268 \pm 0.06089 \%$; unpaired $t$ test; $p=0.0155 ;$ J, normalized expression of Pcdh $\gamma$ A12 mRNA; WT, $1 \pm 0.0923 \% ;$;KO, $0.6785 \pm 0.0057 \% ;$ unpaired $t$ test; $p=0.0322) .{ }^{*} p<0.05,{ }^{* *} p<0.01$, ${ }^{* * *} p<0.001,{ }^{* * * *} p<0.0001$.

deletion in adulthood and its roles in the cortex-dependent remote memory. The differences in the results also may arise from the difference in the mouse lineage background, as it has been previously reported that recombination patterns and according phenotypes of the same Cre mouse line may differ due to the genetic background and breeding strategies (Fex et al., 2007; GilSanz et al., 2015). Also, for the RNA-seq experiment, Sams et al. (2016) used hippocampal tissue from 10-week-old mice, whereas we used CTCF KD cortical cultures, which can also account for the difference in the data. The early lethality observed in the previous study (Sams et al., 2016) may be due to the apoptosis of pyramidal cells, which was not detected in our mice at the age used in this study. Therefore, further investigations are needed to find the exact mechanisms underlying the differences between the two studies. Also, it may be interesting to explore the agedependent role of CTCF in neurons because the timing of the protein deletion accounts for the main difference between the two CTCF cKO mouse lines. It may be plausible to think that CTCF changes its main regulatory function in the brain with the age.
To our knowledge, this is the first study to reveal the CTCF function in excitatory and inhibitory neurons of mammalian adult brain in relation to remote memory. We have found a novel association between CTCF, a central molecule for 3D genome architecture, and remote memory. Our study provides a valuable set of data for future studies. For example, our CTCF-deficient mice can be used as a remote memory-impairment mouse model to study the difference in the mechanisms of recent and remote memory. Also, human genome is known to have many CTCF binding sites (Kim et al., 2007), and it has been reported that several de novo mutations in CTCF have been found in individuals with intellectual disability (Gregor et al., 2013). Moreover, RNA-seq of inhibitory neurons will be able to more accurately define CTCF's role in inhibitory neurons. In this study, we performed LTP field recording to examine how CTCF dysfunction in inhibitory cells affects excitatory cells and found that LTP (fEPSP) was normal. A future experiment, such as patch-clamp recording of inhibitory neurons, may reveal that CTCF dysfunction alters electrical properties or functional connectivity of inhibitory neurons. Further investigations on DEGs from our 
RNA-seq data may provide more information on how CTCFmediated genome architecture supports permanent memories to last and help develop therapeutics for patients suffering from disorders with long-term memory deficits, such as dementia.

\section{References}

Ashburner M, Ball CA, Blake JA, Botstein D, Butler H, Cherry JM, Davis AP, Dolinski K, Dwight SS, Eppig JT, Harris MA, Hill DP, Issel-Tarver L, Kasarskis A, Lewis S, Matese JC, Richardson JE, Ringwald M, Rubin GM, Sherlock G (2000) Gene ontology: tool for the unification of biology. The gene ontology consortium. Nat Genet 25:25-29. CrossRef Medline

Bonev B, Cavalli G (2016) Organization and function of the 3D genome. Nat Rev Genet 17:661-678. CrossRef Medline

Bouwman BA, de Laat W (2015) Getting the genome in shape: the formation of loops, domains and compartments. Genome Biol 16:154. CrossRef Medline

Chen J, Bardes EE, Aronow BJ, Jegga AG (2009) ToppGene suite for gene list enrichment analysis and candidate gene prioritization. Nucleic Acids Res 37:W305-W311. CrossRef Medline

Einarsson EÖ, Pors J, Nader K (2015) Systems reconsolidation reveals a selective role for the anterior cingulate cortex in generalized contextual fear memory expression. Neuropsychopharmacology 40:480-487. CrossRef Medline

Fex M, Wierup N, Nitert MD, Ristow M, Mulder H (2007) Rat insulin promoter 2-cre recombinase mice bred onto a pure C57BL/6J background exhibit unaltered glucose tolerance. J Endocrinol 194:551-555. CrossRef Medline

Filippova GN, Fagerlie S, Klenova EM, Myers C, Dehner Y, Goodwin G, Neiman PE, Collins SJ, Lobanenkov VV (1996) An exceptionally conserved transcriptional repressor, CTCF, employs different combinations of zinc fingers to bind diverged promoter sequences of avian and mammalian c-myc oncogenes. Mol Cell Biol 16:2802-2813. CrossRef Medline

Frankland PW, Bontempi B (2005) The organization of recent and remote memories. Nat Rev Neurosci 6:119-130. CrossRef Medline

Frankland PW, O'Brien C, Ohno M, Kirkwood A, Silva AJ (2001) [alpha]CaMKII-dependent plasticity in the cortex is required for permanent memory. Nature 411:309-313. CrossRef Medline

Frankland PW, Bontempi B, Talton LE, Kaczmarek L, Silva AJ (2004) The involvement of the anterior cingulate cortex in remote contextual fear memory. Science 304:881-883. CrossRef Medline

Gaszner M, Felsenfeld G (2006) Insulators: exploiting transcriptional and epigenetic mechanisms. Nat Rev Genet 7:703-713. CrossRef Medline

Gil-Sanz C, Espinosa A, Fregoso SP, Bluske KK, Cunningham CL, MartinezGaray I, Zeng H, Franco SJ, Müller U (2015) Lineage tracing using Cux2-cre and Cux2-CreERT2 mice. Neuron 86:1091-1099. CrossRef Medline

Goshen I, Brodsky M, Prakash R, Wallace J, Gradinaru V, Ramakrishnan C, Deisseroth K (2011) Dynamics of retrieval strategies for remote memories. Cell 147:678-689. CrossRef Medline

Gregor A, Oti M, Kouwenhoven EN, Hoyer J, Sticht H, Ekici AB, Kjaergaard S, Rauch A, Stunnenberg HG, Uebe S, Vasileiou G, Reis A, Zhou H, Zweier C (2013) De novo mutations in the genome organizer CTCF cause intellectual disability. Am J Hum Genet 93:124-131. CrossRef Medline

Guo Y, Monahan K, Wu H, Gertz J, Varley KE, Li W, Myers RM, Maniatis T, Wu Q (2012) CTCF/cohesin-mediated DNA looping is required for protocadherin alpha promoter choice. Proc Natl Acad Sci U S A 109: 21081-21086. CrossRef Medline

Guo Y, Xu Q, Canzio D, Shou J, Li J, Gorkin DU, Jung I, Wu H, Zhai Y, Tang Y, Lu Y, Wu Y, Jia Z, Li W, Zhang MQ, Ren B, Krainer AR, Maniatis T, Wu Q (2015) CRISPR inversion of CTCF sites alters genome topology and Enhancer/Promoter function. Cell 162:900-910. CrossRef Medline

Headley DB, Paré D (2017) Common oscillatory mechanisms across multiple memory systems. Sci Learn 2:1. CrossRef

Hirayama T, Tarusawa E, Yoshimura Y, Galjart N, Yagi T (2012) CTCF is required for neural development and stochastic expression of clustered pcdh genes in neurons. Cell Rep 2:345-357. CrossRef Medline

Holwerda SJ, de Laat W (2013) CTCF: the protein, the binding partners, the binding sites and their chromatin loops. Philos Trans R Soc Lond B Biol Sci 368:20120369. CrossRef Medline

Huang W, Zhu PJ, Zhang S, Zhou H, Stoica L, Galiano M, Krnjević K, Roman G, Costa-Mattioli M (2013) mTORC2 controls actin polymerization re- quired for consolidation of long-term memory. Nat Neurosci 16:441448. CrossRef Medline

Igaz LM, Bekinschtein P, Vianna MM, Izquierdo I, Medina JH (2004) Gene expression during memory formation. Neurotox Res 6:189-204. CrossRef Medline

Kang SJ, Liu MG, Chen T, Ko HG, Baek GC, Lee HR, Lee K, Collingridge GL, Kaang BK, Zhuo M (2012) Plasticity of metabotropic glutamate receptordependent long-term depression in the anterior cingluate cortex after amputation. J Neurosci 32:11318-11329. CrossRef Medline

Kim S, Kim T, Lee HR, Jang EH, Ryu HH, Kang M, Rah SY, Yoo J, Lee B, Kim JI, Lim CS, Kim SJ, Kim UH, Lee YS, Kaang BK (2016) Impaired learning and memory in CD38 null mutant mice. Mol Brain 9:16. CrossRef Medline

Kim TH, Abdullaev ZK, Smith AD, Ching KA, Loukinov DI, Green RD, Zhang MQ, Lobanenkov VV, Ren B (2007) Analysis of the vertebrate insulator protein CTCF-binding sites in the human genome. Cell 128 : 1231-1245. CrossRef Medline

Kornblihtt AR (2012) CTCF: from insulators to alternative splicing regulation. Cell Res 22:450-452. CrossRef Medline

Lee SH, Lim CS, Park H, Lee JA, Han JH, Kim H, Cheang YH, Lee SH, Lee YS, Ko HG, Jang DH, Kim H, Miniaci MC, Bartsch D, Kim E, Bailey CH, Kandel ER, Kaang BK (2007) Nuclear translocation of CAM-associated protein activates transcription for long-term facilitation in Aplysia. Cell 129:801-812. CrossRef Medline

Li B, Dewey CN (2011) RSEM: accurate transcript quantification from RNA-seq data with or without a reference genome. BMC Bioinformatics 12:323. CrossRef Medline

Liu Q, Trotter J, Zhang J, Peters MM, Cheng H, Bao J, Han X, Weeber EJ, Bu G (2010) Neuronal LRP1 knockout in adult mice leads to impaired brain lipid metabolism and progressive, age-dependent synapse loss and neurodegeneration. J Neurosci 30:17068-17078. CrossRef Medline

Maurano MT, Wang H, John S, Shafer A, Canfield T, Lee K, Stamatoyannopoulos JA (2015) Role of DNA methylation in modulating transcription factor occupancy. Cell Rep 12:1184-1195. CrossRef Medline

Medrano-Fernández A, Barco A (2016) Nuclear organization and 3D chromatin architecture in cognition and neuropsychiatric disorders. Mol Brain 9:83. CrossRef Medline

Miller CA, Gavin CF, White JA, Parrish RR, Honasoge A, Yancey CR, Rivera IM, Rubio MD, Rumbaugh G, Sweatt JD (2010) Cortical DNA methylation maintains remote memory. Nat Neurosci 13:664-666. CrossRef Medline

Nagayoshi T, Isoda K, Mamiya N, Kida S (2017) Hippocampal calpain is required for the consolidation and reconsolidation but not extinction of contextual fear memory. Mol Brain 10:61. CrossRef Medline

Nichols MH, Corces VG (2015) A CTCF code for 3D genome architecture. Cell 162:703-705. CrossRef Medline

Ong CT, Corces VG (2014) CTCF: an architectural protein bridging genome topology and function. Nat Rev Genet 15:234-246. CrossRef Medline

Park P, Volianskis A, Sanderson TM, Bortolotto ZA, Jane DE, Zhuo M, Kaang BK, Collingridge GL (2014) NMDA receptor-dependent long-term potentiation comprises a family of temporally overlapping forms of synaptic plasticity that are induced by different patterns of stimulation. Philos Trans R Soc Lond B Biol Sci 369:20130131. CrossRef Medline

Peixoto L, Abel T (2013) The role of histone acetylation in memory formation and cognitive impairments. Neuropsychopharmacology 38:62-76. CrossRef Medline

Pombo A, Dillon N (2015) Three-dimensional genome architecture: players and mechanisms. Nat Rev Mol Cell Biol 16:245-257. CrossRef Medline

Ren G, Jin W, Cui K, Rodriguez J, Hu G, Zhang Z, Larson DR, Zhao K (2017) CTCF-mediated enhancer-promoter interaction is a critical regulator of cell-to-cell variation of gene expression. Mol Cell 67:1049-1058.e6. Medline

Restivo L, Vetere G, Bontempi B, Ammassari-Teule M (2009) The formation of recent and remote memory is associated with time-dependent formation of dendritic spines in the hippocampus and anterior cingulate cortex. J Neurosci 29:8206-8214. CrossRef Medline

Robinson MD, McCarthy DJ, Smyth GK (2010) edgeR: a Bioconductor package for differential expression analysis of digital gene expression data. Bioinformatics 26:139-140. CrossRef Medline 
Rossetti T, Banerjee S, Kim C, Leubner M, Lamar C, Gupta P, Lee B, Neve R, Lisman J (2017) Memory erasure experiments indicate a critical role of CaMKII in memory storage. Neuron 96:207-216.e2. CrossRef Medline

Sams DS, Nardone S, Getselter D, Raz D, Tal M, Rayi PR, Kaphzan H, Hakim O, Elliott E (2016) Neuronal CTCF is necessary for basal and experiencedependent gene regulation, memory formation, and genomic structure of BDNF and Arc. Cell Rep 17:2418-2430. CrossRef Medline

Takehara-Nishiuchi K, Nakao K, Kawahara S, Matsuki N, Kirino Y (2006) Systems consolidation requires postlearning activation of NMDA receptors in the medial prefrontal cortex in trace eyeblink conditioning. J Neurosci 26:5049-5058. CrossRef Medline

Teixeira CM, Pomedli SR, Maei HR, Kee N, Frankland PW (2006) Involvement of the anterior cingulate cortex in the expression of remote spatial memory. J Neurosci 26:7555-7564. CrossRef Medline

Tsien JZ, Chen DF, Gerber D, Tom C, Mercer EH, Anderson DJ, Mayford M, Kandel ER, Tonegawa S (1996) Subregion- and cell type-restricted gene knockout in mouse brain. Cell 87:1317-1326. CrossRef Medline
Wagner GP, Kin K, Lynch VJ (2012) Measurement of mRNA abundance using RNA-seq data: RPKM measure is inconsistent among samples. Theory Biosci 131:281-285. CrossRef Medline

Wan LB, Pan H, Hannenhalli S, Cheng Y, Ma J, Fedoriw A, Lobanenkov V, Latham KE, Schultz RM, Bartolomei MS (2008) Maternal depletion of CTCF reveals multiple functions during oocyte and preimplantation embryo development. Development 135:2729-2738. CrossRef Medline

Wang H, Hu Y, Tsien JZ (2006) Molecular and systems mechanisms of memory consolidation and storage. Prog Neurobiol 79:123-135. CrossRef Medline

Yates A, Akanni W, Amode MR, Barrell D, Billis K, Carvalho-Silva D, Cummins C, Clapham P, Fitzgerald S, Gil L, Girón CG, Gordon L, Hourlier T, Hunt SE, Janacek SH, Johnson N, Juettemann T, Keenan S, Lavidas I, Martin FJ, et al. (2016) Ensembl 2016. Nucleic Acids Res 44:D710D716. CrossRef Medline

Yu NK, Baek SH, Kaang BK (2011) DNA methylation-mediated control of learning and memory. Mol Brain 4:5. CrossRef Medline 